\title{
PRODUCTION TECHNOLOGY SOLUTIONS TO ENHANCE HEAVY OIL RECOVERY OF MARGINAL FIELDS, OFFSHORE VIETNAM
}

\author{
Tran Quoc Viet, Vu Viet Hung, Nguyen Hai An \\ PetroVietnam Exploration Production Corporation (PVEP) \\ Email: viettq@pvep.com.vn \\ https://doi.org/10.47800/PVJ.2020.10-04
}

\section{Summary}

The finding of heavy oil at Dong Do field of Cuu Long basin is a success in exploration. It could be considered as a large heavy oil field offshore Vietnam. Maximising reserve is a challenge to the operator when they think of a suitable development strategy to efficiently and economically exploit the field. Over the past decades, production technology application in heavy oil production has been widely developed in the industry. Apart from the thermal method, pumping technology makes remarkable advances by enlarging the drawdown created over the conventional gas lift in several heavy oil projects.

This paper presents all the production technology solutions that apply to the marginal heavy oil field offshore Vietnam. One of the major solutions is the electric submersible pump (ESP) and gas-lift (GL) combination method to enhance the wellbore lifting efficiency. In doing so, a series of solutions to improve heavy oil recovery have been conducted from design to pilot test whilst optimising the economic yield over the field life. Among them, the application of ESP and GL combination plays as the key driver to reinforce good production performance.

As a result, the design includes an electrical pump system coupled with GL back-up, all integrated with one to boost production and prolong well life. Beside that, closely monitoring and optimising is one factor to give the pump a longer life.

Key words: Heavy oil, enhanced oil recovery, ESP, diesel injection, Dong Do field.

\section{Introduction}

Heavy oil and bitumen (referred to as heavy oil) are important sources of energy. With an assessed potential of more than 4,000 billion barrels globally, heavy oil is a much larger resource than conventional oil.

At UNITAR 1982 conference in Venezuela, a basic heavy oil definition had been agreed upon as follows: heavy oil is the oil which has a viscosity (at reservoir condition) from 100 to $>10,000 \mathrm{CP}$, and density at $15.6^{\circ} \mathrm{C}$ from 943 to $1,000 \mathrm{~kg} / \mathrm{m}^{3}$ or $<10-20^{\circ} \mathrm{API}$.

Heavy oil is identified based on viscosity and density, or density only if viscosity data are not available. Heavy oil contains about $3 \%$ or more sulfur, and 2,000 ppm vanadium. Nickel and molybdenum are also common.

Heavy oil classification: [1]

Date of receipt: 8/10/2020. Date of review and editing: 8- 30/10/2020. Date of approval: 30/10/2020.
- Type A: Medium heavy oil; density and viscosity in the range of $18-25^{\circ} \mathrm{API}, 10-100 \mathrm{cP}$, respectively; flow in reservoir condition.

- Type B: Heavy/extra-heavy oil; density and viscosity in the range of $7-20^{\circ} \mathrm{API}, 100-10,000 \mathrm{CP}$, respectively; flow in reservoir condition.

- Type $C$ : bitumen; density and viscosity in the range of $7-12^{\circ} \mathrm{API}$, and $>10,000 \mathrm{cP}$, respectively; no flow in reservoir condition.

In March 2010, Dong Do field was discovered by appraisal well DD-3X drilled in the central part of BII.2.20 reservoir. Based on the oil type classification, hydrocarbon in Dong Do field is near a heavy oil zone, which has $20^{\circ} \mathrm{API}$ gravity and $17 \mathrm{CP}$ viscosity. The question how to develop this heavy oil at maximum recovery rate and lowest cost was raised from early. Using the ESP lift system to produce heavy oil from only one formation is a preferable concept for this marginal field development with high challenges. 
The application of ESP has been common in the industry but still less in Vietnam. Operators from the neighbouring field employed ESP as an alternative in the case of gas lift system unavailability. But application in this project is to enhance artificial lift efficiency in heavy oil production. This paper introduces a systematic approach to design an efficient dual artificial lift system with ESP and GL combination to enhance the production of the heavy oil reservoir.

\section{The heavy oil development concept}

\subsection{Heavy oil global and Vietnam resource}

Heavy oil reserves are widely distributed around the world. According to the Barrels in Place statistics of heavy oil, its spread are mainly in North-South America, Russia, Europe, the Middle East, and China as shown in Figure 2.

In Vietnam, there are currently two fields, namely Dong Do and Kinh Ngu Vang, where heavy oil has been discovered. Table 1 shows the heavy oil resource of Dong Do and Kinh Ngu Vang fields, and BII.2.20 is presently the largest heavy oil reservoir offshore Vietnam.

\subsection{Heavy oil production technology}

Due to the characteristics of heavy oil with high viscosity and low dissolved gas content, traditional recovery methods are often less applicable. Recovery in the primary stage is usually very low with an average rate of approximately $5 \%$ only. The assisted recovery methods applied include the thermal and non-thermal methods (Figure 3).

\subsection{Heavy oil recovery factor}

The heavy oil production methods as shown in Figure 4 have been applied in many parts of the world, bringing positive results with recovery factor up to more than $30 \%$.

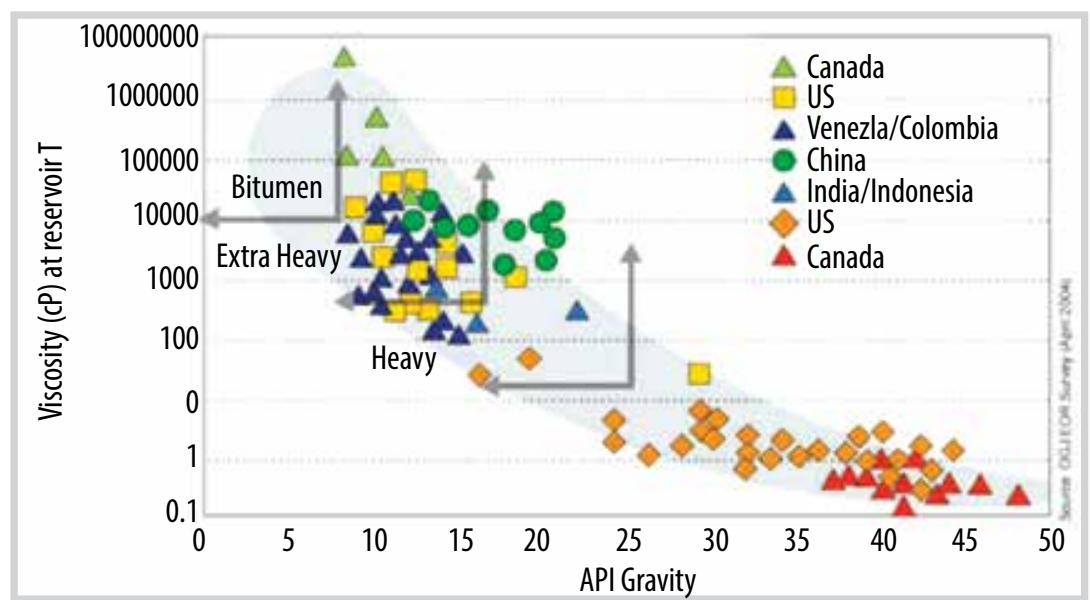

Figure 1. Heavy oil type classification [1].

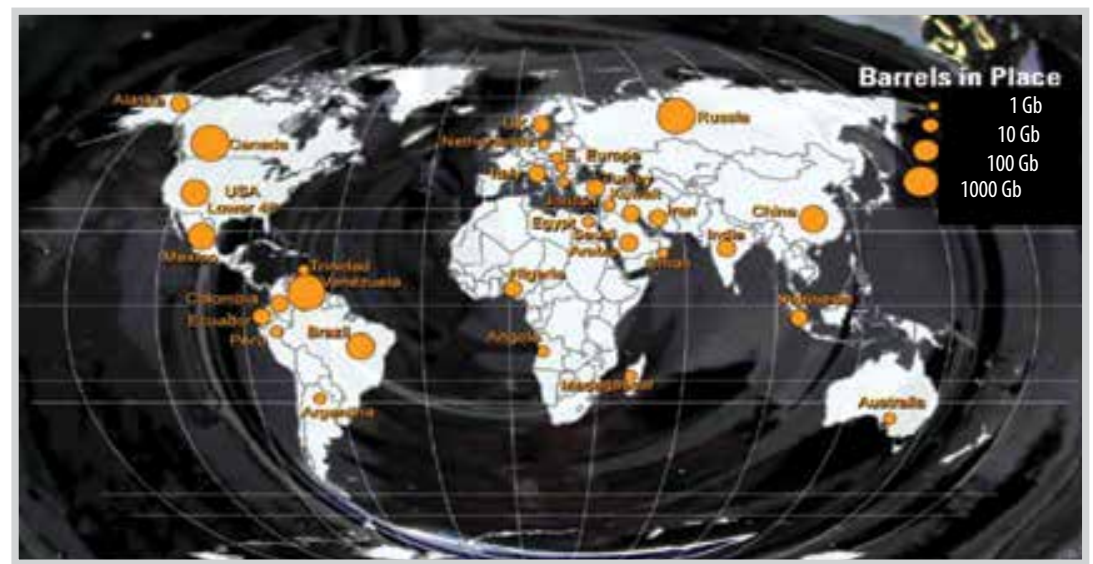

Figure 2. Heavy oil resources [1].

Table 1. Heavy oil in place of Dong Do and Kinh Ngu Vang fields

\begin{tabular}{|c|c|c|c|c|c|c|}
\hline \multirow[t]{2}{*}{ Field } & \multirow[t]{2}{*}{ Formation } & \multirow[t]{2}{*}{ Reservoir } & \multicolumn{3}{|c|}{$\begin{array}{c}\text { OlIP-P50 } \\
\text { (million standard } \\
\text { barrels) }\end{array}$} & \multirow[t]{2}{*}{ Remarks } \\
\hline & & & $1 \mathrm{P}$ & $2 \mathrm{P}$ & $3 P$ & \\
\hline \multirow{5}{*}{$\begin{array}{l}\text { Dong } \\
\text { Do }\end{array}$} & \multirow{5}{*}{ Miocene } & Blll sand & & 8.2 & 8.2 & \multirow{2}{*}{$\begin{array}{l}\text { Development reserves, } \\
\text { not yet produced }\end{array}$} \\
\hline & & BII.2.10 & & 1.6 & 1.6 & \\
\hline & & BII.2.20 & 101.5 & 101.5 & 101.5 & \multirow{2}{*}{$\begin{array}{l}\text { Development reserves, } \\
\text { in production }\end{array}$} \\
\hline & & BII.2.30 & 24.4 & 24.4 & 24.4 & \\
\hline & & BI.2.30 & & 3.2 & 4.3 & $\begin{array}{l}\text { Development reserves, } \\
\text { not yet produced }\end{array}$ \\
\hline \multirow{3}{*}{$\begin{array}{l}\text { Kinh } \\
\text { Ngu } \\
\text { Vang }\end{array}$} & \multirow{3}{*}{ Miocene } & BII.1.10 & 24.3 & 27.5 & 27.5 & \multirow{3}{*}{$\begin{array}{l}\text { Reserves, not yet } \\
\text { developed }\end{array}$} \\
\hline & & BII.1.20 & & 9.9 & 9.9 & \\
\hline & & Intra BI.1 & 15.1 & 21.4 & 21.4 & \\
\hline \multicolumn{3}{|c|}{ Total } & 165.3 & 197.7 & 198.6 & \\
\hline
\end{tabular}

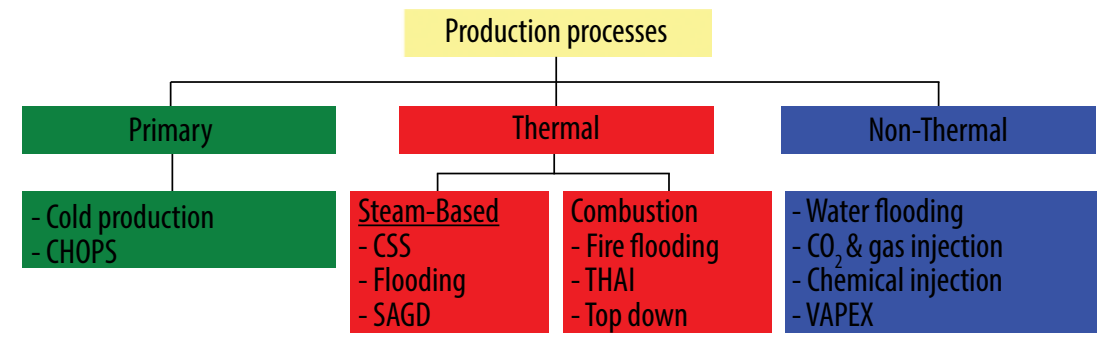

Figure 3. Heavy oil production technology [2]. 


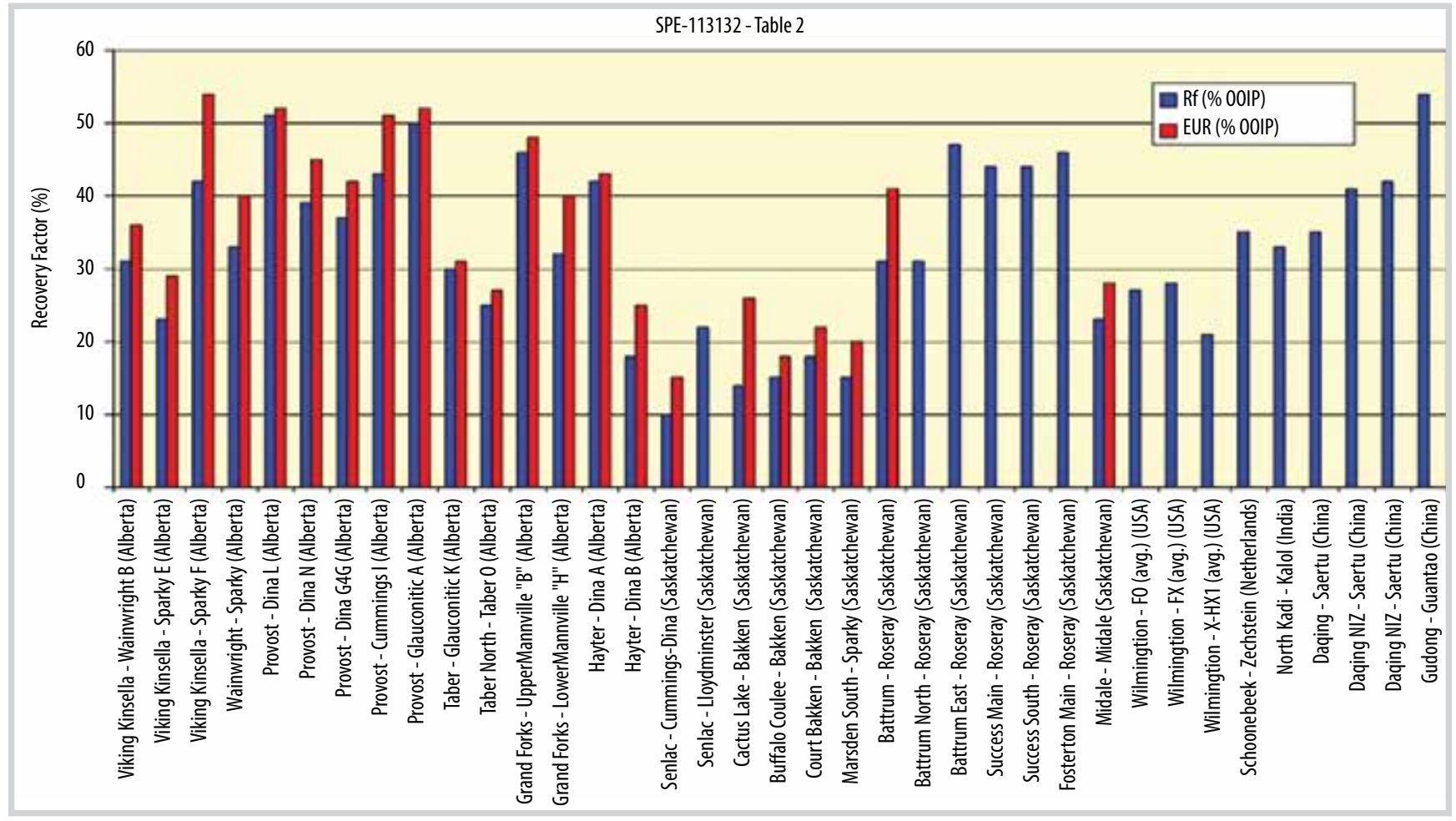

Figure 4. Heavy oil recovery factor [2].

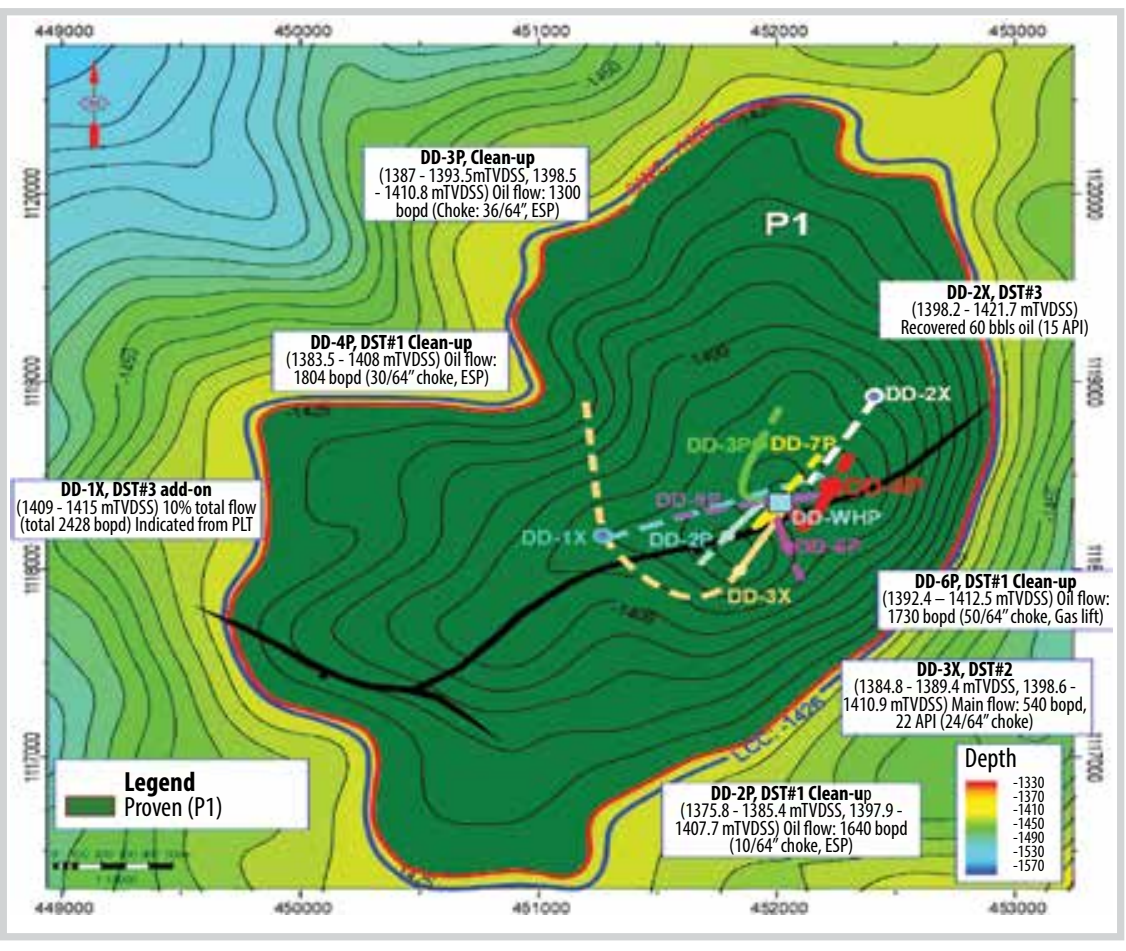

Figure 5. Dong Do heavy oil top reservoir map.

\section{Designing heavy oil production technology for marginal fields offshore Vietnam}

\subsection{Dong Do heavy oil reservoir}

Dong Do field is located in the northwest of Block 02/97 in the northeast area of Cuu Long basin. Three pay zones were discovered in the Middle Miocene
Upper - Lower Con Son formations (BII.2.20, BII.2.30 and Bll.1.10) in wildcat wells $A, B$ and $C$ as stacked channel sandstones trapped. Each gross sandstone package is about 30 - $40 \mathrm{~m}$ thick, capped above by 10 - 30 $\mathrm{m}$ of shale/clay stones.

The diversity of fluid properties $\left(20^{\circ} \mathrm{API}\right)$ made it difficult to select the production technology method to enhance wellbore lifting efficiency.

\subsection{Designing submersible electric pump and gas-lift in Dong Do field [3]}

Similar data to simulate the submersible electric pump mining (ESP) model are calculated based on well parameters, fluid parameters, and referring to the seam test results with $\mathrm{N}_{2}$-lift-gas support. The results show that ESP's performance is better than that of $\mathrm{N}_{2}$-lift-gas with the stable flow reaching 1,500 barrels per day. ESP can work well with the water cut increase to $80-90 \%$ and lower critical pressure and creates 


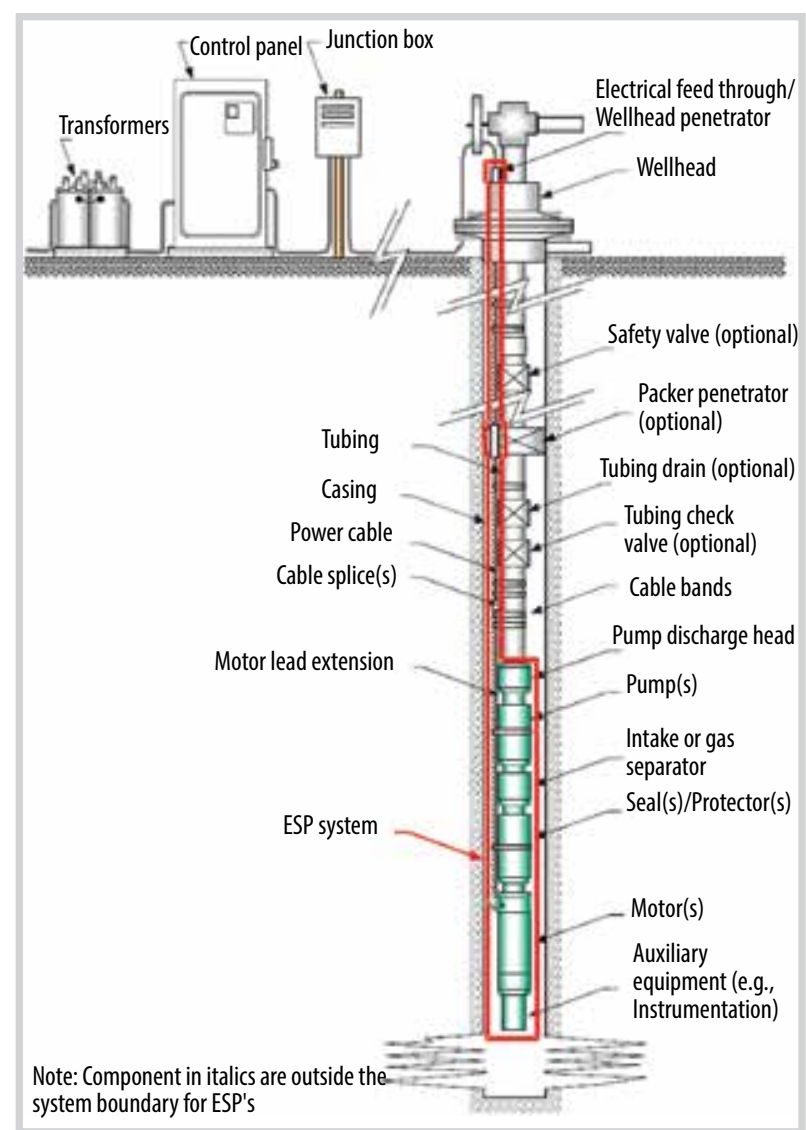

Figure 6. Single ESP system [3].

a larger drawdown. This will help the recovery factor to be higher than the GL method. ESP adds energy to the well, increasing the well-productivity. The equipment has a huge advantage over the GL method in extracting heavy oil with a small oil-gas ratio. This method helps improve the extraction rate to compensate for the decrease in oil flow and increase the flow of exploitation water. To optimise the production capacity of the well, the submersible electric pump will be applied to the Middle Miocene reservoir of Dong Do field (BII.2.20 and BII.2.30). The production wells will then be completed with a submersible electric pump combined with a backup gas system from the beginning. The submersible electric pump will be placed at the appropriate depth in the well completion equipment to optimise the extraction flow and be able to work in harsh environments (sand, $\mathrm{H}_{2} \mathrm{~S}$ ). The schematic diagram of the well equipment using the basic submersible electric pump is illustrated in Figure 6.

Figure 7 shows the equipment string where GL system is placed above ESP packer to provide a backup system as well as optimisation capability in case of simultaneous production by both ESP and GL $[3,4]$.

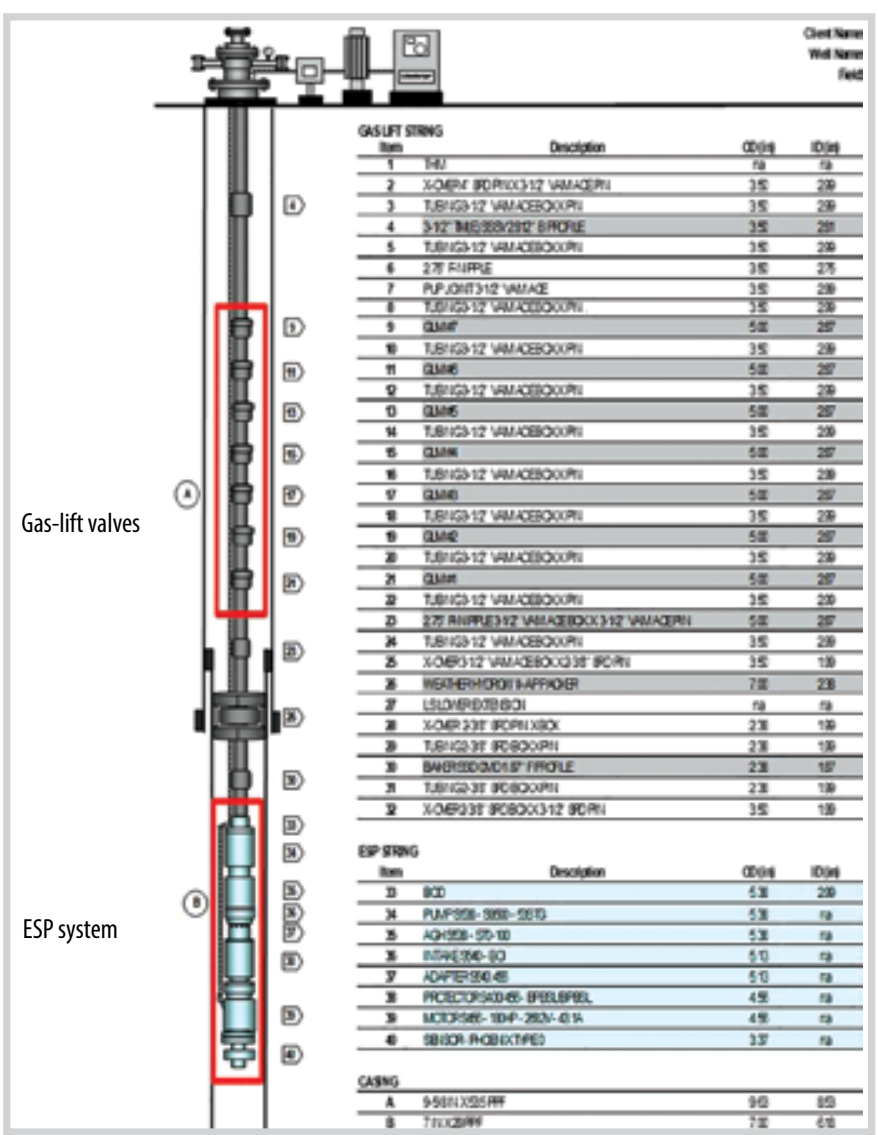

Figure 7. ESP and GL combination system schematic.

\subsection{Improving heavy oil recovery solutions}

Many solutions to improve heavy oil production have been conducted by simulation model, such as infill wells, water/gas injection, polymer, and diesel injection. The results of the simulations also indicate the difficulty of enhancing heavy oil recovery. Most of them showed reverse recovery factors, except infill wells with the densely well pattern and diesel injection. Thus, diesel injection has been conducted in reality with positive results, and infill well is proposed in the next phase as a major solution to enhance heavy oil recovery in BII.2.20 Dong Do field.

\subsubsection{Infill with the dense well pattern}

Based on the research results of the reservoir simulation model, the infill well cases were evaluated, then the optimal number, position, and trajectory were selected for Bll.2.20 reservoir. The results showed that one infill well for each reservoir is the optimal case. The results are shown in Figure 8.

The application of commingling wells has been evaluated. However, the results showed that it is ineffective for this case. 


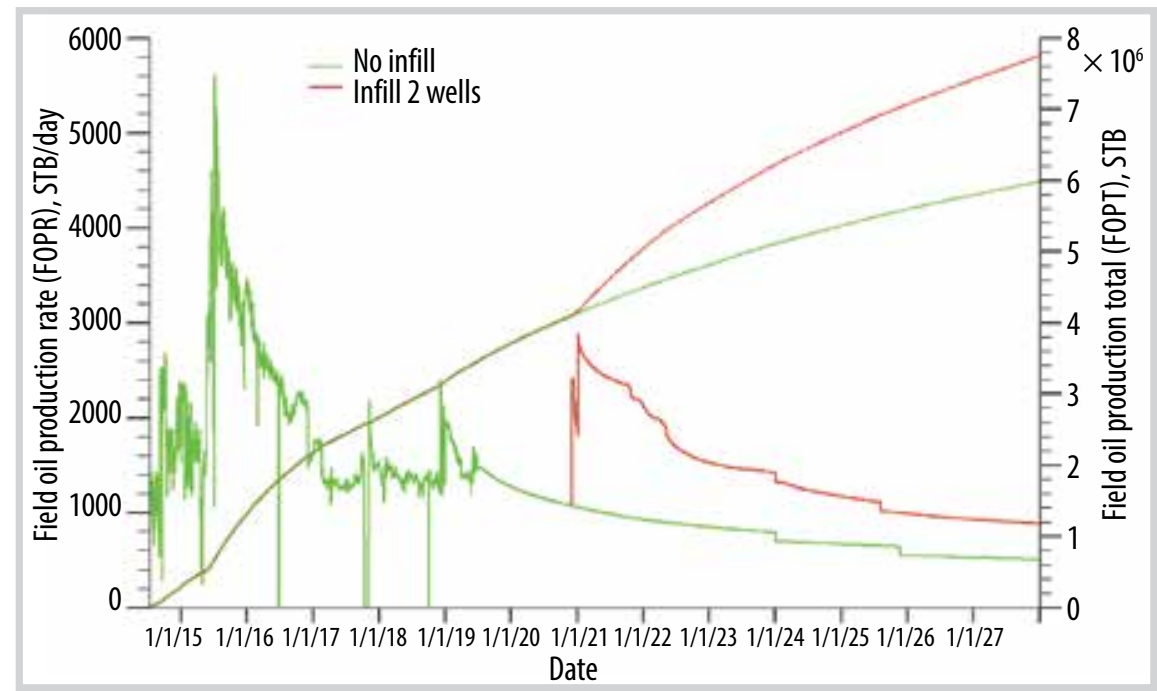

Figure 8. Oil recovery in case of infill well into Bll.2.20 reservoir.

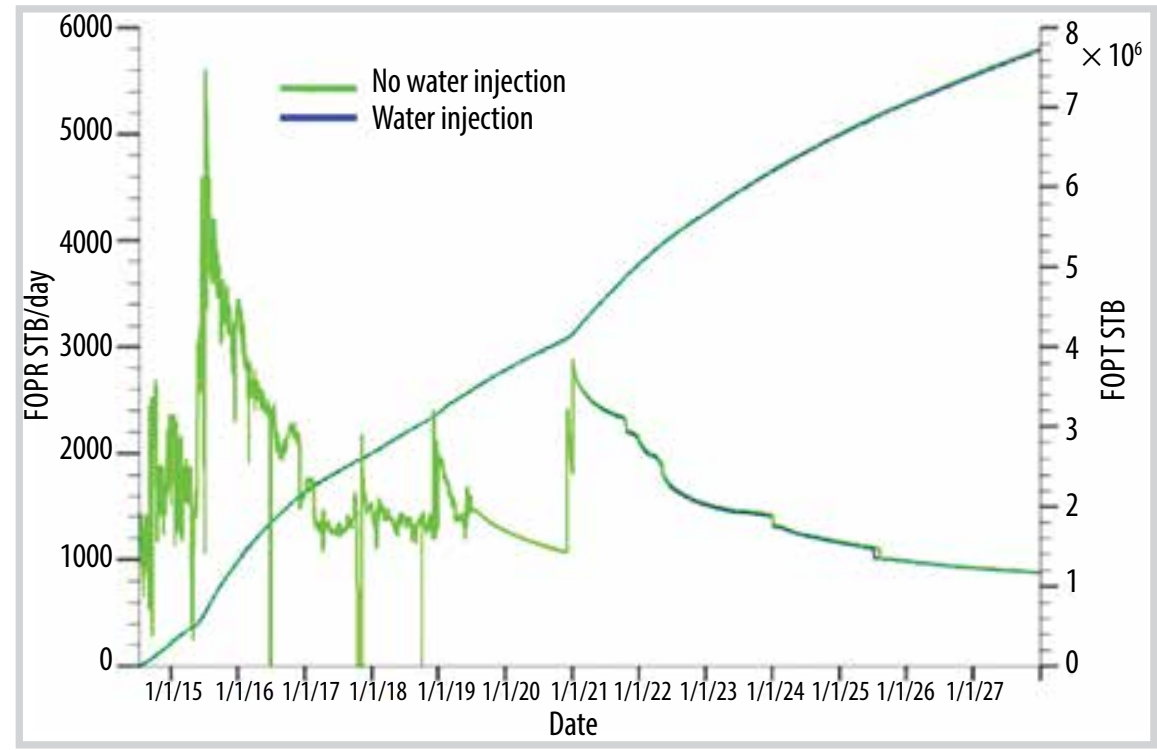

Figure 9. Oil recovery in case of water injection into BII.2.20 reservoir.

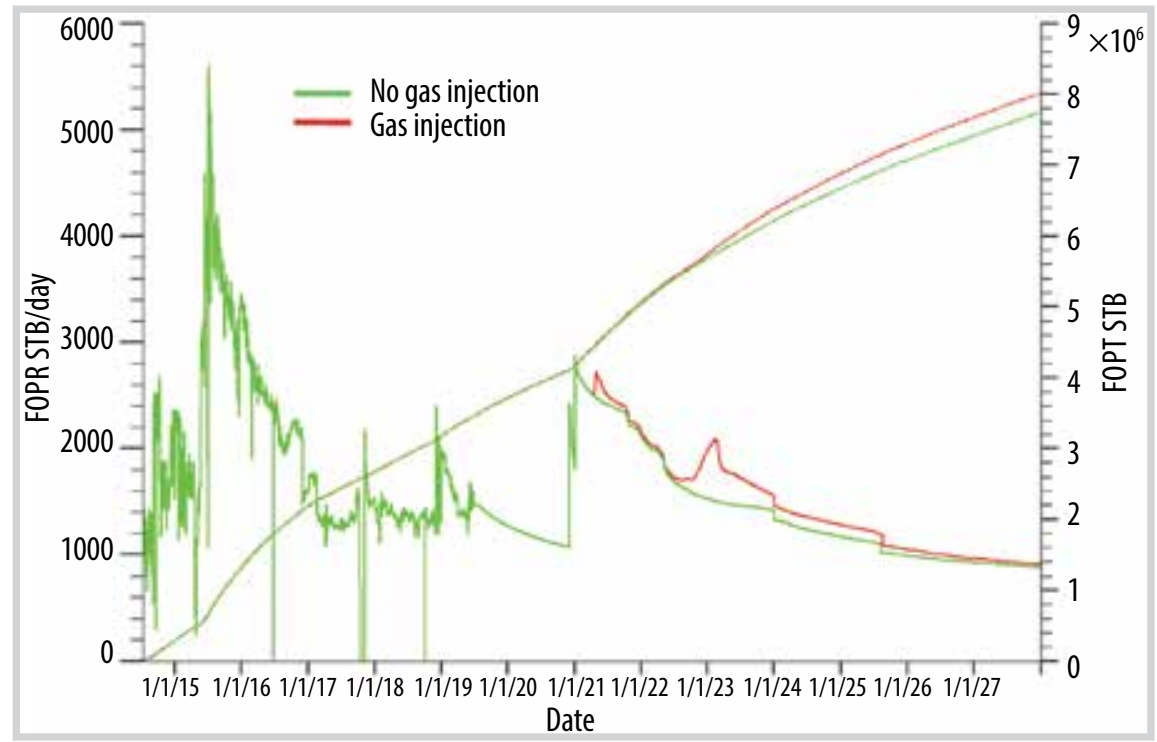

Figure 10. Oil recovery in case of gas injection into BII.2.20.

\subsubsection{Water injection}

According to the results of research based on reservoir simulation, due to the relatively heavy oil fluid nature, water injection is not an effective solution for maintaining reservoir pressure. The results are shown in Figure 9.

Besides that, the case of combined injection in both reservoirs has been evaluated. However, this also results in poor recovery.

\subsubsection{Gas injection}

Both cases of converting producers which have low oil rate ( $<100$ standard barrels per day) to the gas injector and drilling new gas injectors have been evaluated. The results show that gas injection is ineffective in the case of converting producers to injectors. In contrast, in the case of infill two producers and two injectors, the gas injection is effective, however, the oil incremental is insignificant. The results are shown in Figure 10.

\subsubsection{Water alternating gas}

Similar to the gas injection cases, evaluation of the case of maintaining reservoir pressure to improve the oil recovery factor by water alternating gas injection (WAG) showed that it is insignificantly efficient for BII.2.20 heavy oil reservoir. The results are shown in Figure 11.

\subsubsection{Polymer injection}

The cases of polymer injection have been studied. However, it is also ineffective in improving oil recovery. The results are shown in Figure 12.

\subsubsection{Diesel injection}

In the case of shutting-in high water cut production wells, the 
water volume will settle down near the wellbore. After re-opening, the oil rate will be reduced, and the water cut is higher than before shutting-in. This phenomenon is caused by the effect of hysteresis that reduces oil relative permeability. The application of this hysteresis phenomenon can maintain production for high water cut wells after the shut-in stage by injecting non-wetting fluid (diesel). The re-starting of wells after the long shut-in period is easy and the oil production increases by about $20-30 \%$. Figure 13 shows the actual oil rate jumps up and the water cut drops down with diesel injection [5].

\section{Application results}

Up to now, there have been four production wells drilled into BII.2.20 reservoir (DD-2P, DD-3P, DD-4P, and DD-6P), and one well into Bll.2.30 reservoir (DD-7P). All of the wells are completed with ESPs that operate at the designed flow rate of about $1,500 \mathrm{bbl} /$ day [4]. The flow range operates at a higher efficiency than the initial design. The ESPs have been operating for more than 5 years beyond the manufacturer's recommended replacement time limit (2.5 - 3.0 years) as shown in Figure 14.

The actual pump life longer than recommended by the manufacturer revealed the optimal production technology from design to operation. In summary, the success of ESP application in the heavy oil Dong Do field could come from the following:

- Exact evaluation of the rock - fluid, and reservoir performance (low temperature and pressure, low dissolved gas).

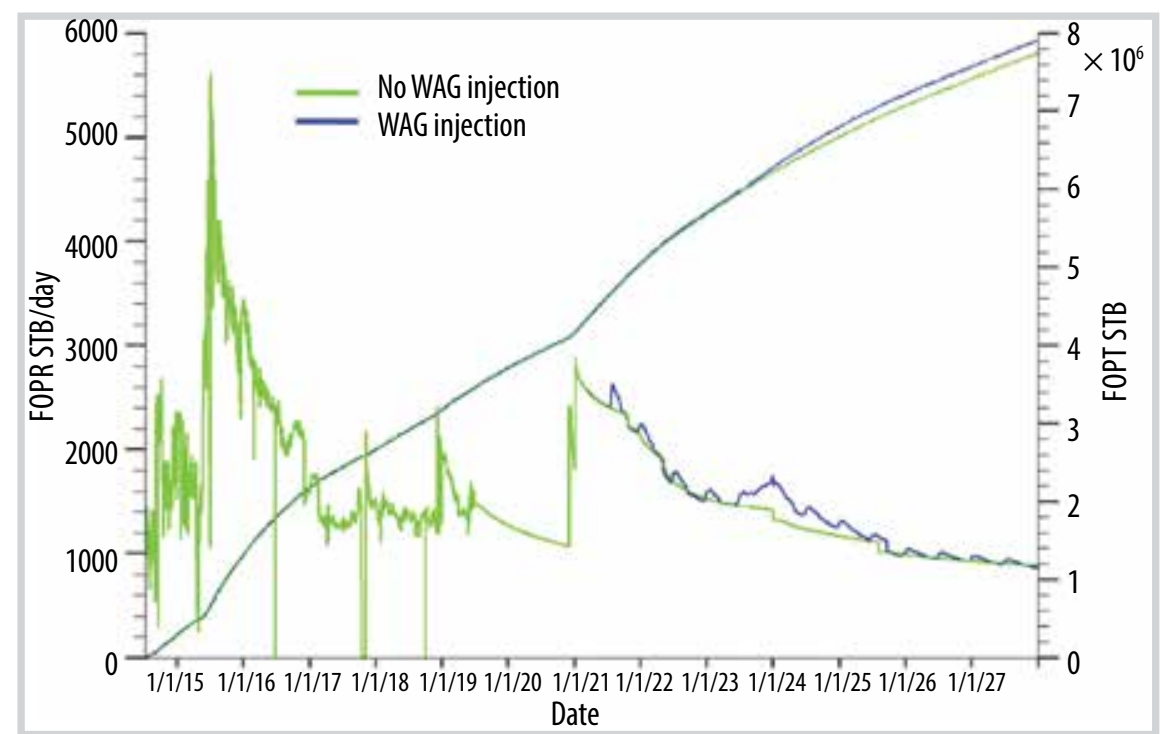

Figure 11. Oil recovery in case of water alternating gas injection into BII.2.20 and BII.2.30.

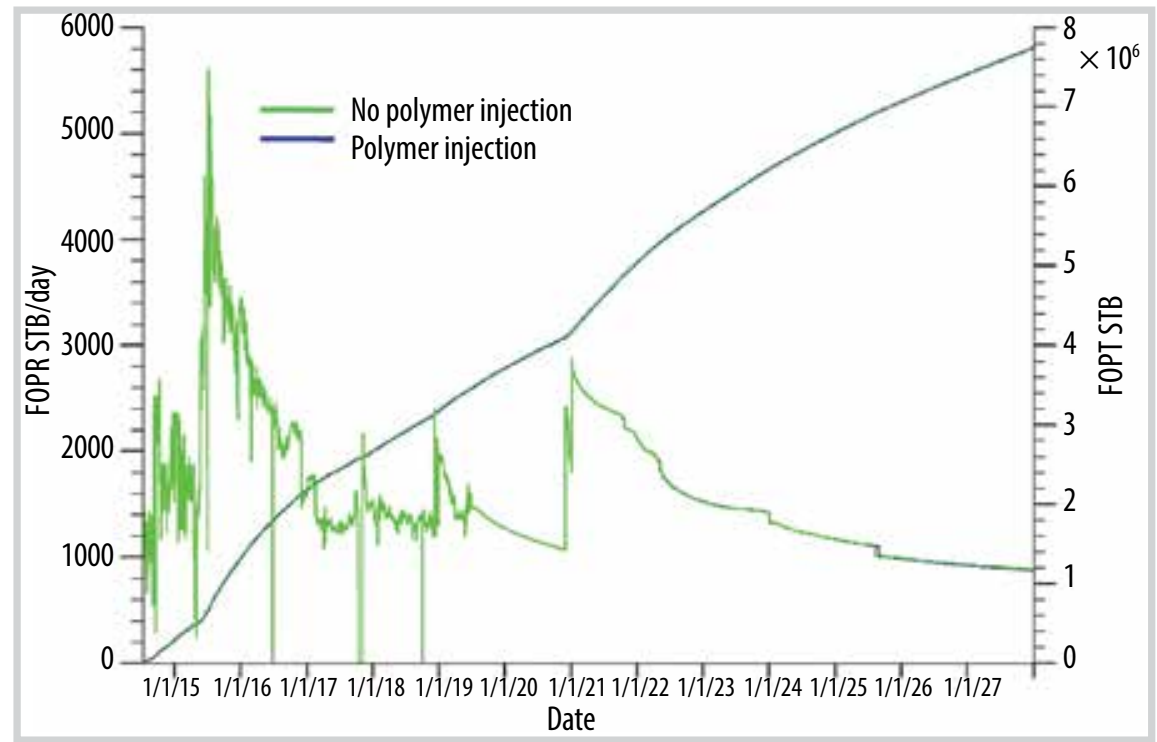

Figure 12. Oil recovery in case of polymer injection into BII.2.20 reservoir.

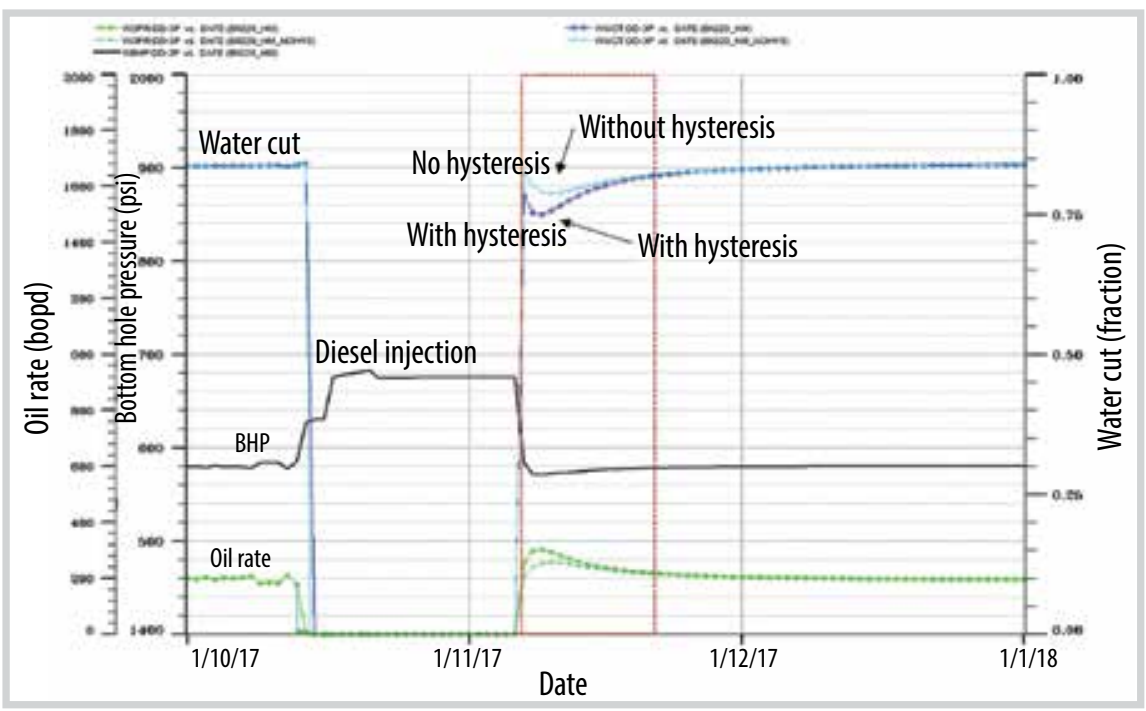

Figure 13. Simulation results of diesel injection application for ESP well. 


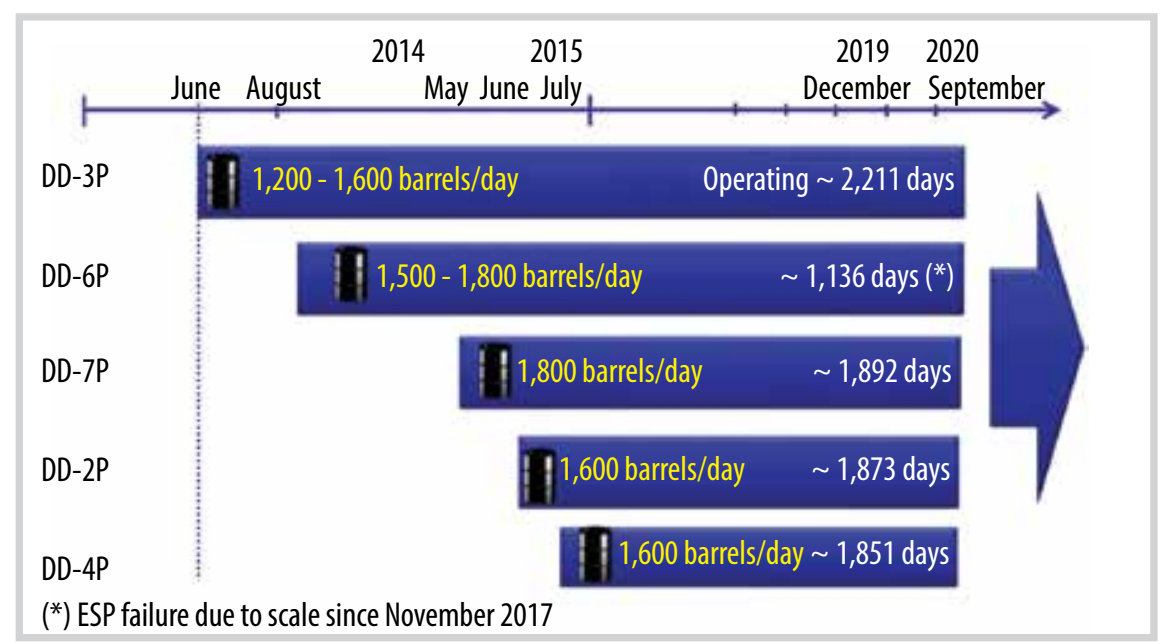

Figure 14. Current ESP's life in Dong Do field.

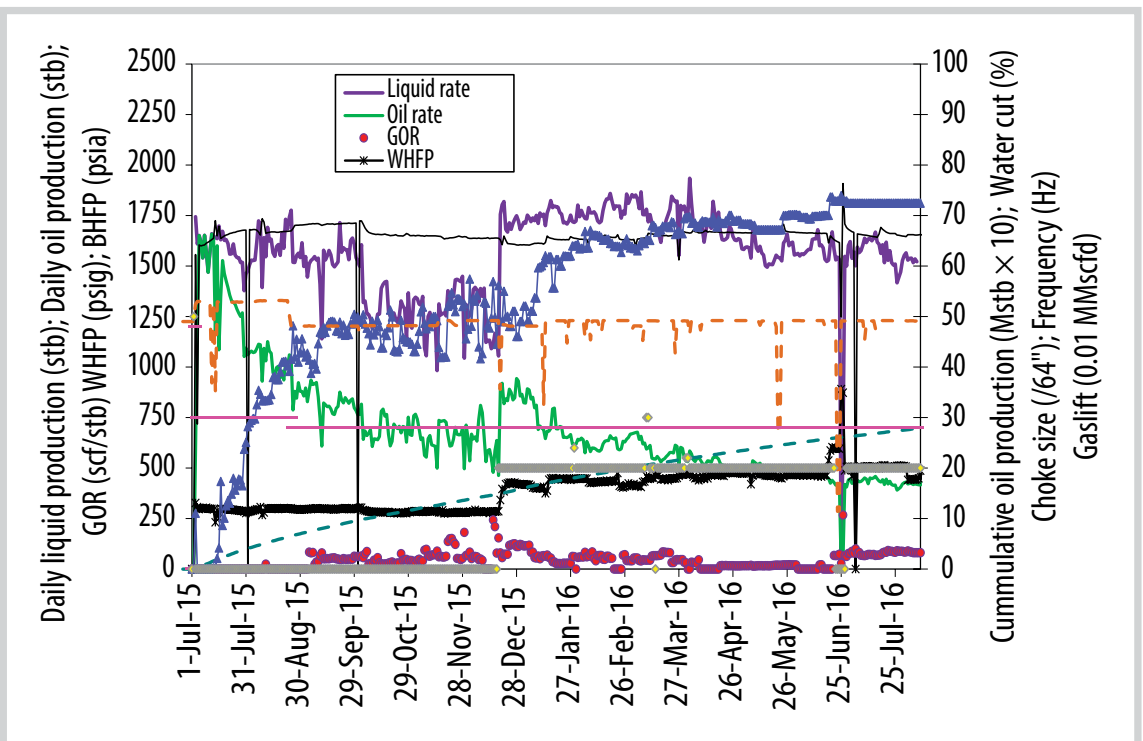

Figure 15. Well production performance with ESP \& gas-lift combination.

Table 2. Summary well test points for ESP + GL system analysis

\begin{tabular}{|l|c|c|c|}
\hline \multicolumn{1}{|c|}{ Parameters } & Test A & Test B & Test C \\
\hline Liquid rates (standard barrel per day) & 1,340 & 1,740 & $\mathbf{1 , 8 3 0}$ \\
\hline Water cut (\%) & 72 & 72 & $\mathbf{7 2}$ \\
\hline WHP (psi) & 294 & 441 & $\mathbf{4 4 8}$ \\
\hline Gas-lift rate (MMscfd) & 0 & 0.2 & $\mathbf{0 . 2 8}$ \\
\hline Pump discharge pressure (psi) & 2,140 & 2,060 & $\mathbf{2 , 0 5 2}$ \\
\hline Pump intake pressure (psi) & 1,670 & 1,650 & $\mathbf{1 , 6 6 4}$ \\
\hline Frequency (Hz) & 49 & 49 & $\mathbf{4 9}$ \\
\hline HP (KVA) & 31.8 & 31.2 & $\mathbf{3 1}$ \\
\hline
\end{tabular}

- Good design for lower and upper completion (with sand-screen to avoid the sand production).

- Suitable selection of production technology with ESP and gas-lift back up.

- Continuously monitoring and optimising ESP.

- Studying new solution to improve ESP performance and enhance heavy oil recovery.
One of the important solutions actually applied is ESP and GL combination. Figure 15 shows the production performance with primary ESP and dual artificial lift system in the pilot test period (Dec2015).

Varied injection gas-lift rate is tested to analyse the behaviour of ESP when supported by GL technique. Table 2 summarised the production performance and ESP action with and without GL (given the same choke size and frequency).

Three flow test points were systematically examined with: (A) only ESP, (B) ESP and GL 0.2 MMscfd, and (C) ESP and GL 0.28 MMscf as illustrated in Table 2. The incremental liquid between Test $A$ and Test $B$ is quite considerable around $30 \%$ and continues rising with more gas injected. It is noted that the power consumption also slightly reduces by $2 \%$ as a result of a lighter fluid column above the pump created by gas-lift injection. Reducing power consumption is one of the crucial factors helping ESP have a longer life.

One of the solutions improving heavy oil recovery is diesel injection which has been applied in reality. DD-3P in BII.2.20 has selected diesel injection to the wellbore. Before shut-in, DD-3P produced with high water cut, up to $89 \%$, and oil rate at 185 standard barrels per day. After applying diesel injection, the results showed that the well restarted quickly and reached 350 standard barrels per day (except the amount of diesel injection). The oil rate was higher, about 165 standard barrels per day $(+85 \%)$; water cut decreased from $89 \%$ to $76 \%$ [5]. This better production condition 


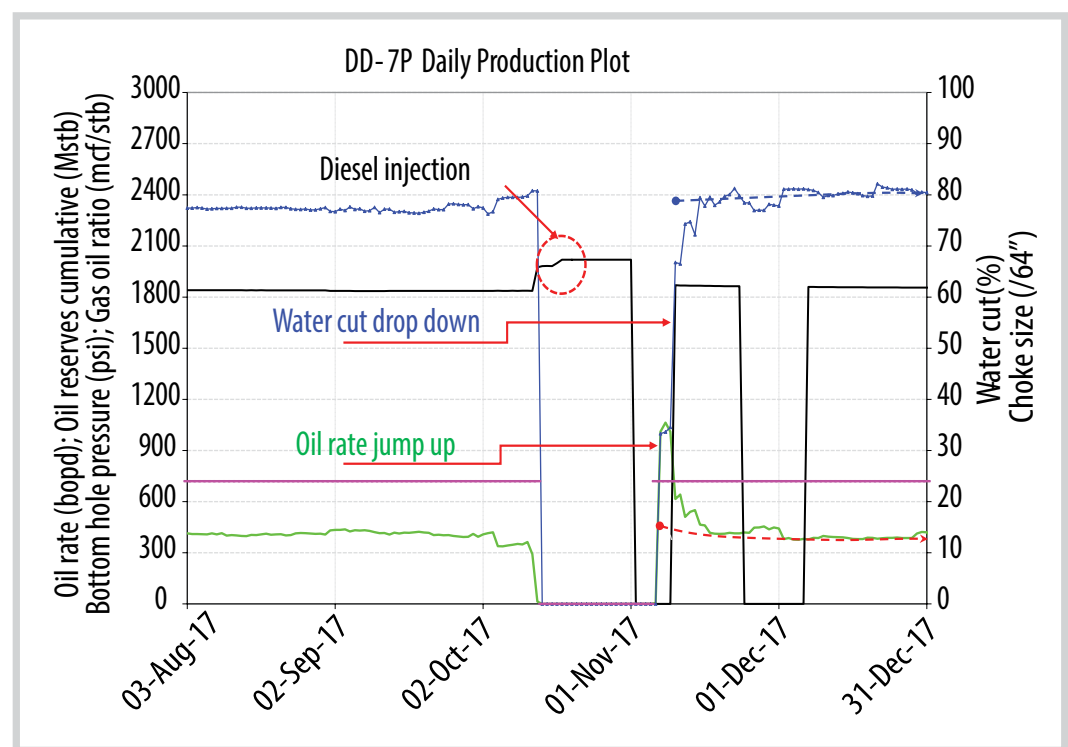

Figure 16. Diesel injection solution applied to Dong Do heavy oil reservoir [5].

maintained for 1 month, then the well returned to the previous conditions as before diesel injection.

Up to date, ESP in Dong Do heavy oil reservoir has been operating in good performance (excluding 1 ESP failure due to scale). To achieve the success, selecting suitable production technology (hereby ESP and $\mathrm{GL}$ backup) is the priority. Moreover, solutions to improve heavy oil production have been studied and commenced with the best results, respectively as diesel injection.

\section{Conclusion and recommendation}

Heavy oil discovery in a marginal field in Cuu Long basin, offshore Vietnam is an exploration success and puts forward challenges for field development. Selecting suitable production technology in cost-effective and high-efficiency concepts is the key factor to maximise heavy oil recovery in Dong Do field.

Prudent study of solutions to improve heavy oil production is essential. Dual artificial lift systems (ESP supported by GL) help reduce pump workload downtime and provide the flexible capacity to ramp up production when necessary. The combination of ESP and GL system allows the pump to operate beyond its designed frequency/flow rates which ultimately results in a cost-saving of replacing the new pump and improving oil recovery factor.

Diesel injection is a good solution to improve oil production which has been proved by actual results. This solution should be recommended to other operators when the production flows with high water cut.

\section{References}

[1] Abha Dwivedy, "Steam generation by solar and natural gas generators for thermal enhanced oil recovery", Master Science Thesis, West Virginia University, USA.

[2] Dennis Beliveau, "Waterflooding viscous oil reservoirs", SPE Reservoir Evaluation \& Engineering, Vol. 12, No. 5, pp. 689 - 701, 2009. DOI: 10.2118/113132-PA.

[3] S.T. Tran, H.V. Vu, V.M. Le, T.N. Nguyen, L.H. Nguyen, P. Prajunla, and H.M.H. Dong, "Hybrid system of ESP and gas lift application from conceptual design, pilot test to system analysis", SPE Middle East Artificial Lift Conference and Exhibition held in Manama, Kingdom of Bahrain, 30 November - 1 December, 2016. DOI: 10.2118/184215-MS.

[4] Vu Viet Hung and Tran Thai Son, "Production technology designed for heavy oil recovery of a marginal field offshore Vietnam", Science and Technology Development Journal, Vol. 19, No.1, pp. 190 - 202, 2016. DOI: 10.32508/stdj.v19i1.516.

[5] Lê Minh Vũ, Nguyễn Đức Đông, Cao Hữu Bình và Vũ Việt Hưng, "Duy trì khai thác dầu cho giếng có hàm lượng nước cao sau quá trình đóng giếng bằng phương pháp bơm diesel", Tạp chí Dâu khí, Số 1, trang 20 - 29, 2020. 